\title{
Glycemic Over- and Undertreatment in VA Nursing Home Residents with Type 2 Diabetes: a Retrospective Cohort Study
}

\author{
Lauren Lederle, $M D^{\top} \mathbb{D}$, Bocheng Jing, $M S^{2}$, Annette Rodriguez, $M A^{2}$, \\ Lauren J. Hunt, RN, PhD, FNP-BC ${ }^{3}$, and Sei J. Lee, MD, MAS $S^{2,4}$
}

'Division of Hospital Medicine, San Francisco VA Medical Center , San Francisco , CA , USA; ${ }^{2}$ Division of Geriatrics, University of California, San Francisco, San Francisco, CA , USA; ${ }^{3}$ Department of Physiological Nursing, UCSF , San Francisco , CA , USA; ${ }^{4}$ Geriatrics and Extended Care Service, San Francisco VA Medical Center, San Francisco, CA , USA.

J Gen Intern Med 35(6):1900-2

DOI: $10.1007 / \mathrm{s} 11606-019-05479-5$

(c) Society of General InternalMedicine (This is aU.S. government work and not under copyright protection in the U.S.; foreign copyright protection may apply) 2019

\section{INTRODUCTION}

For nursing home $(\mathrm{NH})$ residents, clinical guidelines recommend less stringent hemoglobin $\mathrm{A} 1 \mathrm{c}(\mathrm{HbAl})$ targets between 7.5 and $9.0 \% \%^{1-3}$ while avoiding medications with higher hypoglycemia risks such as insulin. Previous studies in community-dwelling older adults have suggested that overly intensive glycemic treatment may be common. ${ }^{4,5}$ However, little is known about current glycemic treatment practices among NH residents with type 2 diabetes mellitus (T2DM). Our objective was to determine the rates of glycemic overtreatment (defined as insulin use with $\mathrm{HbAlc}<6.5 \%$ ) and glycemic undertreatment (defined as no glucose-lowering medications with $\mathrm{HbAlc} \geq 8.5 \%$ ) in older adults recently admitted to the $\mathrm{NH}$.

\section{METHODS}

We conducted a retrospective cohort study of Veterans Affairs (VA) nursing home residents over age 65 with T2DM from January 1, 2013, to December 31, 2015. We defined diabetes as $\mathrm{HbA} 1 \mathrm{c}>6.5 \%$ or use of glucose-lowering medication (GLM) in the year prior to NH admission. Residents with ICD codes for type 1 diabetes, length of stay (LOS) < 30 days, hospice stays, or with no $\mathrm{HbAlc}$ measurement during NH stay were excluded. We identified the date of the first $\mathrm{HbAlc}$ during $\mathrm{NH}$ stay (index $\mathrm{HbAlc}$ date) and categorized $\mathrm{NH}$ residents into five mutually exclusive categories based on glucose-lowering medication (GLM) use on the index HbA1c date: (1) no glucose-lowering medications, (2) metformin use without use of any other GLMs, (3) use of other oral GLMs in any combination (but without insulin use), (4) any short-acting

Received August 7, 2019

Accepted October 2, 2019

Published online November 8, 2019 insulin use (in combination with oral GLMs or alone, but without use of long-acting insulin), (5) any long-acting insulin use. We defined likely overtreatment as $\mathrm{HbAlc}<6.5$ with any insulin use, and likely undertreatment as $\mathrm{HbAlc} \geq 8.5$ with no GLM use. This study was reviewed and approved by the University of California, San Francisco Committee on Human Research.

\section{RESULTS}

We identified 5471 VA NH residents who met inclusion and exclusion criteria. Mean age was 74.5, all were male, and 54\% had NH LOS > 90 days. Our cohort had a high comorbidity burden (mean Charlson Comorbidity Index of 6) and most were dependent on several activities of daily living (Table 1). The index HbAlc was within the first 30 days of $\mathrm{NH}$ admission in $62 \%$ of residents.

Seven percent were on metformin alone, $9 \%$ were on oral GLMs without insulin, $12 \%$ were on short-acting insulin without long-acting insulin use, and $46 \%$ were on long-acting insulin (alone or in combination with short-acting insulin or oral GLMs). Of residents with HbA1c < 6.5\%, 38\% (762/1998) were receiving insulin and of all patients on insulin and $55 \%$ (1717/3137) had an Alc of $<7.5 \%$. Of the $5471 \mathrm{NH}$ residents, 762 (14\%) met criteria for likely overtreatment, while $76(1.4 \%)$ met criteria for likely undertreatment (Table 2).

\section{DISCUSSION}

In a national sample of VA NH residents, we found that $14 \%$ were likely overtreated with $\mathrm{HbAlc}<6.5$ while receiving insulin. A much smaller proportion of $\mathrm{NH}$ residents (1.4\%) were likely undertreated, with $\mathrm{HbA} 1 \mathrm{c} \geq 8.5 \%$ while taking no GLMs. Given that $62 \%$ of our cohort's index AbA1c occurred within 30 days of $\mathrm{NH}$ admission, our results reflect the fact that glycemic treatments that were appropriate when older adults were healthier and community-dwelling may become inappropriate when older adults become more frail and transition into the NH. Thus, glycemic overtreatment appears to be 
Table 1 Characteristics of Nursing Home Residents

\begin{tabular}{|c|c|}
\hline & Mean (SD) or $N(\%)$ \\
\hline & $N=\mathbf{5 4 7 1}$ \\
\hline Age, mean (SD) & $74.5(8 \%)$ \\
\hline Male, $N(\%)$ & $5471(100 \%)$ \\
\hline A1c, mean (SD) & $7.1(1.4)$ \\
\hline \multicolumn{2}{|l|}{ Hemoglobin A1C, $N(\%)$} \\
\hline$<6.5$ & $2058(36 \%)$ \\
\hline $6.5-7.4$ & $1651(30 \%)$ \\
\hline $7.5-8.4$ & $1025(19 \%)$ \\
\hline$\geq 8.5$ & $797(15 \%)$ \\
\hline \multicolumn{2}{|l|}{ Time from $\mathrm{NH}$ admission to Alc measurement, $N(\%)$} \\
\hline 1-30 days & $3372(62 \%)$ \\
\hline$>30$ days & $2099(38 \%)$ \\
\hline \multicolumn{2}{|l|}{ Glucose-lowering medication (GLM) category, $N(\%)^{*}$} \\
\hline No GLM & $1470(27 \%)$ \\
\hline Metformin alone & $387(7 \%)$ \\
\hline Use of other oral GLMs & $477(9 \%)$ \\
\hline Short-acting insulin use & $645(12 \%)$ \\
\hline Long-acting insulin use & $2492(46 \%)$ \\
\hline \multicolumn{2}{|l|}{ Length of NH stay, $N(\%)$} \\
\hline $30-59$ & $1619(30 \%)$ \\
\hline $60-89$ & $888(16 \%)$ \\
\hline $90+$ & $2964(54 \%)$ \\
\hline Hypoglycemia during NH stay (glucose $\leq 50 \mathrm{mg} / \mathrm{dL}), N(\%)$ & $1077(20 \%)$ \\
\hline Hyperglycemia during NH stay (glucose $\geq 400 \mathrm{mg} / \mathrm{dL}$ ), $N(\%)$ & $1374(25 \%)$ \\
\hline ED visit during NH stay, $N(\%)$ & $125(2 \%)$ \\
\hline Charlson Comorbidity Index (CCI), mean (SD) & $6(3.0)$ \\
\hline Minimum Data Set-Activities of Daily Living (MDS-ADL) score, mean (SD) ${ }^{\dagger}$ & $15.3(7.8)$ \\
\hline
\end{tabular}

*Escalating categories of glucose-lowering medication (GLM) use are mutually exclusive. I.e., residents in the "short-acting insulin use" category maybe taking metformin or other oral GLMs but are by definition not using long-acting insulins

$+M D S-A D L$ score ranges from 0 (completely independent) to 28 (totally dependent) in 7 ADLs

Table 2 Rates of Glycemic Treatment by Hemoglobin A1C Category (\%)

\begin{tabular}{|c|c|c|c|c|}
\hline & $<6.5 \%(\mathrm{~N}=1998)$ & $6.5-7.4 \%(\mathrm{~N}=1651)$ & $7.5-8.4 \%(\mathrm{~N}=1025)$ & $\geq 8.5 \%(N=797)$ \\
\hline No GLM $(N=1,470)$ & $872(15.9)$ & $397(7.3)$ & $125(2.3)$ & $76(1.4)$ \\
\hline Metformin alone $(\mathrm{N}=387)$ & $196(3.6)$ & $130(2.4)$ & $47(0.9)$ & $14(0.3)$ \\
\hline Use of other oral GLMs (N=477) & $168(3.1)$ & $169(3.1)$ & $91(1.7)$ & $49(0.9)$ \\
\hline Short acting insulin use $(\mathrm{N}=645)$ & $217(4.0)$ & $222(4.1)$ & $122(2.2)$ & $84(1.5)$ \\
\hline Long Acting Insulin use $(\mathrm{N}=2,492)$ & $545(10.0)$ & $733(13.4)$ & $640(11.7)$ & $574(10.5)$ \\
\hline
\end{tabular}

Percent of total $N=5471$

common among recently admitted NH residents, suggesting that $\mathrm{NH}$ admission may be an opportune time for re-evaluating and de-intensifying glycemic treatments.

Strengths of our study include our large national sample of NH residents with linked pharmacy and laboratory data. Limitations include our reliance on VA administrative and electronic health record data, resulting in a $100 \%$ male sample, and the possibility of the inclusion of small number of type 1 diabetes patients.

Our study found that glycemic overtreatment is common among NH residents with insulin often being used in the setting of HbA1c levels that are below the recommended target levels for NH residents. Given the high burden of hypoglycemia in NH residents, ${ }^{6}$ our results suggest that deintensification interventions focused on decreasing GLMs in $\mathrm{NH}$ residents may be high yield and potentially lead to decreased rates of hypoglycemia.
Corresponding Author: Lauren Lederle, MD; Division of Hospital MedicineSan Francisco VA Medical Center, San Francisco, CA, USA (e-mail: Lauren.lederle@ucsf.edu).

\section{Compliance with ethical standards:}

This study was reviewed and approved by the University of California, San Francisco Committee on Human Research.

Conflict of interest: The authors have no conflicts of interest to report

\section{REFERENCES}

1. Association AD. 11. Older Adults: Standards of Medical Care in Diabetes-2018. Diabetes Care. 2018;41(Supplement 1):S119-S125. https:// doi.org/10.2337/dc18-S011.

2. Munshi MN, Florez H, Huang ES, et al. Management of diabetes in longterm care and skilled nursing facilities: a position statement of the 
American Diabetes Association. Diabetes Care. 2016;39(2):308-318. https://doi.org/10.2337/dc15-2512.

3. Conlin PR, Colburn J, Aron D, Pries RM, Tschanz MP, Pogach L. Synopsis of the 2017 U.S. Department of Veterans Affairs/U.S. Department of Defense Clinical Practice Guideline: Management of Type 2 Diabetes Mellitus. Ann Intern Med. 2017;167(9):655-663. https://doi. org/10.7326/M17-1362.

4. Lipska KJ, Ross JS, Miao Y, Shah ND, Lee SJ, Steinman MA. Potential overtreatment of diabetes mellitus in older adults with tight glycemic control. JAMA Intern Med. 2015;175(3):356-362. https://doi.org/10. 1001/jamainternmed.2014.7345.

5. Tseng C-L, Soroka O, Maney M, Aron DC, Pogach LM. Assessing potential glycemic overtreatment in persons at hypoglycemic risk. JAMA
Intern Med. 2014;174(2):259-268. https://doi.org/10.1001/ jamainternmed.2013.12963.

6. Newton CA, Adeel S, Sadeghi-Yarandi S, et al. Prevalence, quality of care, and complications in long term care residents with diabetes: a multicenter observational study. J Am Med Dir Assoc. 2013;14(11):842846. https://doi.org/10.1016/j.jamda.2013.08.001.

Publisher's Note Springer Nature remains neutral with regard to jurisdictional claims in published maps and institutional affiliations. 